\title{
Analysis of COVID-19 Outbreak in Iraq from the Perspective of Doctors Working in Iraqi Hospitals
}

\author{
Omar Muayad Abdulkareem Al-Naqeeb \\ Department of surgery, College of medicine, Al-Iraqia Univerity, Baghdad, Iraq \\ Email address: \\ omersurgeon94@gmail.com
}

\section{To cite this article:}

Omar Muayad Abdulkareem Al-Naqeeb. Analysis of COVID-19 Outbreak in Iraq from the Perspective of Doctors Working in Iraqi Hospitals. International Journal of Infectious Diseases and Therapy. Vol. 5, No.2, 2020, pp. 29-33. doi: 10.11648/j.ijidt.20200502.12

Received: April 8, 2020; Accepted: April 24, 2020; Published: May 15, 2020

\begin{abstract}
Background: The COVID-19 is an enveloped RNA enveloped beta coronavirus. In Iraq there were more than 700 cases officially reported for the period from February $24^{\text {th }} 2020$ to April $1^{\text {st }} 2020$ and the case fatality rate was $7.1 \%$. This study aims to determine the most common clinical characteristics of patients who are confirmed as COVID-19 positive in Iraq, as well as to understand the underlying causes which make Iraq have one of the highest case-fatality rates in the world. Methods: A total of 128 doctors working in Iraqi hospitals participated in this study through answering a questionnaire that has been prepared for this purpose. The questionnaire included a set of questions related to the symptoms of the disease, hospital procedures, the level of these procedures and major obstacles. A total of 108 patients who were diagnosed with COVID-19 enrolled in this study to understand the clinical characteristics of COVID-19 in Iraq. Result: The most common symptoms of COVID-19 in Iraq were: fever (seen in $85.2 \%$ of patients), cough (55.6\%), shortness of breath (31.5\%), fatigue (27.8\%), headache $(7.4 \%)$, diarrhea $(1.9 \%)$, and $(9.3 \%)$ were asymptomatic. Initial chest X-rays were abnormal in $(63 \%)$ and lymphopenia was seen in (72.2\%). Most of the doctors $(76.2 \%)$ complained from the unclear guidelines regarding COVID-19 screening and (17.7\%) of suspected cases were not tested for COVID-19. Conclusion: The high fatality rate which seen in Iraq is related to the low level of awareness and late presentation of the patients, in addition to the limited number of the COVID-19 screening tests, unclear guidelines regarding the patients who should be enrolled for the COVID-19 testing, and finally, many of the suspected cases which were reported by doctors were not provided with the necessary tests to confirm the diagnosis. All these together contribute to high fatality rate.
\end{abstract}

Keywords: COVID-19, CORONAVIRUS, Case Fatality Rate, Iraq

\section{Introduction}

The COVID-19 has been identified as an enveloped RNA enveloped beta coronavirus that has been named as severe acute respiratory syndrome coronavirus 2 (SARS-CoV-2) [1, 2]. In February $24^{\text {th }} 2020$, the first case of COVID-19 was confirmed in AL-Najaf - Iraq, then more cases were officially reported [3]. In March $11^{\text {th }} 2020$ the World health organization declared the COVID-19 outbreak as pandemic, which meant the virus will likely spread to all countries on earth [4].

The most common symptoms of the disease include fever, cough, and shortness of breath [5], however many patients who tested positive for COVID-19 were asymptomatic initially [6-8].

The new threat that emerged which is represented by
COVID-19 that put the Iraqi heath system in crisis due to shortage of medication as well as poorly qualified hospitals which put the Iraqi doctors in a challenge due to a lack of equipped facilities [9].

After 37 days of the first case diagnosis, the total number of cases in Iraq is 728 and the case fatality rate is $7.1 \%$ [10, 11] which appears to be extremely high in comparison with the rate in other countries (about 2.3\%) $[12,13]$.

The study aims to determine the most common clinical characteristics of patients who are confirmed as COVID-19 positive in Iraq, as well as to understand the underlying causes which make Iraq have one of the highest case fatality in the world, and this study tries to qualify the procedures and steps taken by specialized authorities to face COVID-19 outbreak and to make clarified recommendations to the ministry of health, medical staff and citizens on the best 
measures to face the COVID-19 outbreak; all of the research goals are discussed from the perspective of doctors who work in Iraqi hospitals.

\section{Study Definitions}

Incubation period: is the interval between the first date of contact with the infection source and the first date of symptom onset

COVID-19 positive (patient): any patient with positive RT-PCR assays which is defined positive in the same manner of the WHO protocol [14].

The normal white cell count is defined by 4,000 to 11,000 white blood cells / $\mu \mathrm{L}$ [15].

Lymphopenia is defined by less than 1500 lymphocytes $/ \mu \mathrm{L}$ of blood in adults and less than 3000 lymphocytes $/ \mu \mathrm{L}$ of blood in children while Lymphocytosis is defined by more than $4000 / \mu \mathrm{L}$ in adults, $7000 / \mu \mathrm{L}$ in older children, and $9000 / \mu \mathrm{L}$ in infants, the patient is diagnosed with absolute lymphocytosis $[16,17]$.

Specialized authorities in this study mean the cell crises in Iraq including the ministry of health.

\section{Methods}

A descriptive (Case series) study was proposed to assess the clinical characteristics of 108 patients who were tested positive for COVID-19 during the period from March $1^{\text {st }}$ 2020 to April $1^{\text {st }} 2020$. All the information is obtained from doctors who have dealt with confirmed COVID 19 positive patients since many of the patients were in quarantine. A questionnaire has been prepared for this purpose which included a set of questions regarding age, gender, clinical symptoms, blood test results, chest $\mathrm{x}$-ray findings, and the fate of the patient.

A second questionnaire was prepared and presented for 128 doctors who work in Iraqi hospitals, and included questions about the number of suspected as well as diagnosed cases and on how doctors working in Iraqi hospitals dealt with those cases and an evaluation on how the authorities dealt with COVID-19 cases, also on knowing the people who were included in the primary screening test. All these questions in order to reach the underlying causes which make Iraq one of the highest case-fatality rates in the world.

RT-PCR assays used as a confirmatory test for COVID-19.

Ethical approvals for this study were in accordance with the ethical standards of the responsible committee of "College of Medicine/ Al-Iraqia University".

The data was analyzing using software program of Statistical Package for the Social Sciences (SPSS) version 24.0.

\section{Results}

A total of 108 patients enrolled in this study, the median age was 46 years; $46.3 \%$ (50 patients) were female and $54.7 \%$ (58 patients) were male. The age distribution is shown in figure 1.

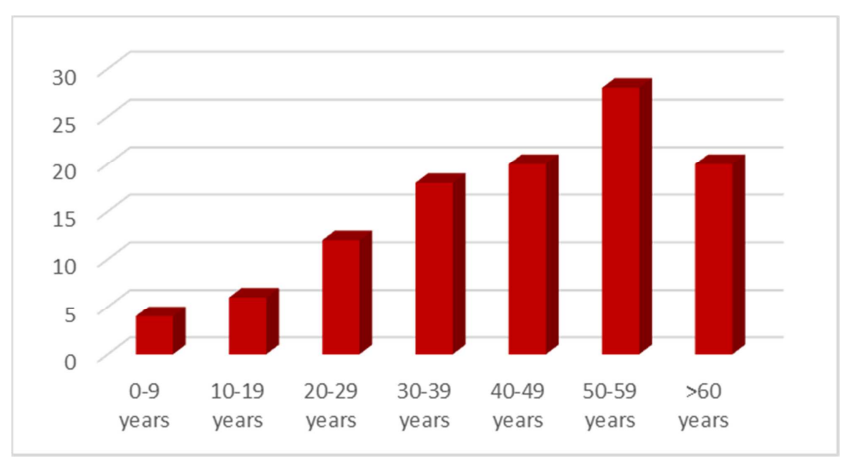

Figure 1. The age distribution of COVID-19 patients.

The most common symptoms were: fever (seen in $85.2 \%$ of patients), cough $(55.6 \%)$, shortness of breath $(31.5 \%)$. However, 10 patients $(9.3 \%)$ were asymptomatic and diagnosed accidentally during screening the contacts as shown in table 1 .

Table 1. Clinical symptoms of COVID-19 patients.

\begin{tabular}{lll}
\hline Symptom & $\begin{array}{l}\text { Number of patients who } \\
\text { show this symptoms at } \\
\text { presentation }\end{array}$ & $\begin{array}{l}\text { Percentage from } \\
\text { the total patient } \\
\text { (108 patients) }\end{array}$ \\
\hline Fever & 92 & $85.2 \%$ \\
Cough & 60 & $55.6 \%$ \\
Shortness of breath & 34 & $31.5 \%$ \\
Fatigue & 30 & $27.8 \%$ \\
Headache & 8 & $7.4 \%$ \\
Diarrhea & 2 & $1.9 \%$ \\
Asymptomatic & 10 & $9.3 \%$ \\
\hline
\end{tabular}

Initial chest $\mathrm{X}$-rays were abnormal in $(63 \%)$ with ground glass opacity was the most finding.

White blood cell count was normal in most of the patients (87\%). However; lymphopenia was seen in $(72.2 \%)$ as shown in table 2 .

Table 2. WBCs and lymphocyte count of COVID-19 patients.

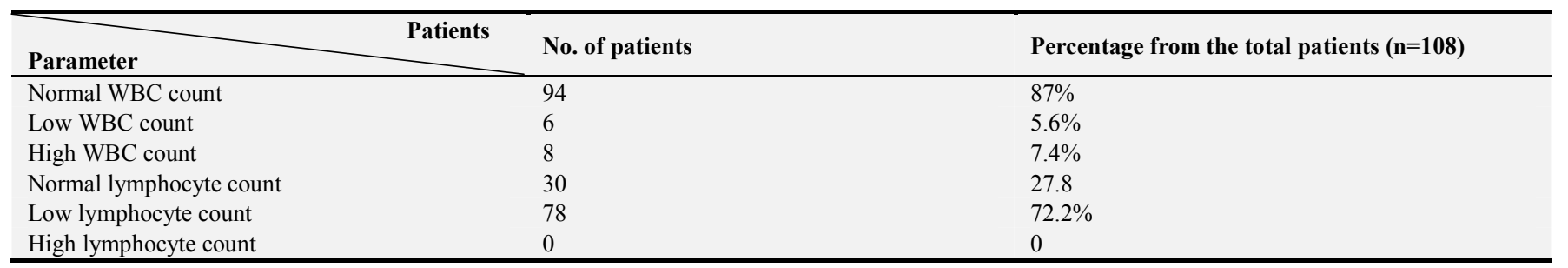

There was a positive traveling history in those patients or their close contact relatives in one of the countries which 
have a high number of people infected with coronavirus in $83.3 \%$.

Unfortunately, 10 of the patients $(9.8 \%)$ who enrolled in the study died, 8 of them died within 24 hours of admission into quarantine and two of them died after 5 days of admission and both of them were in the intensive care unit as shown in the figure 2.

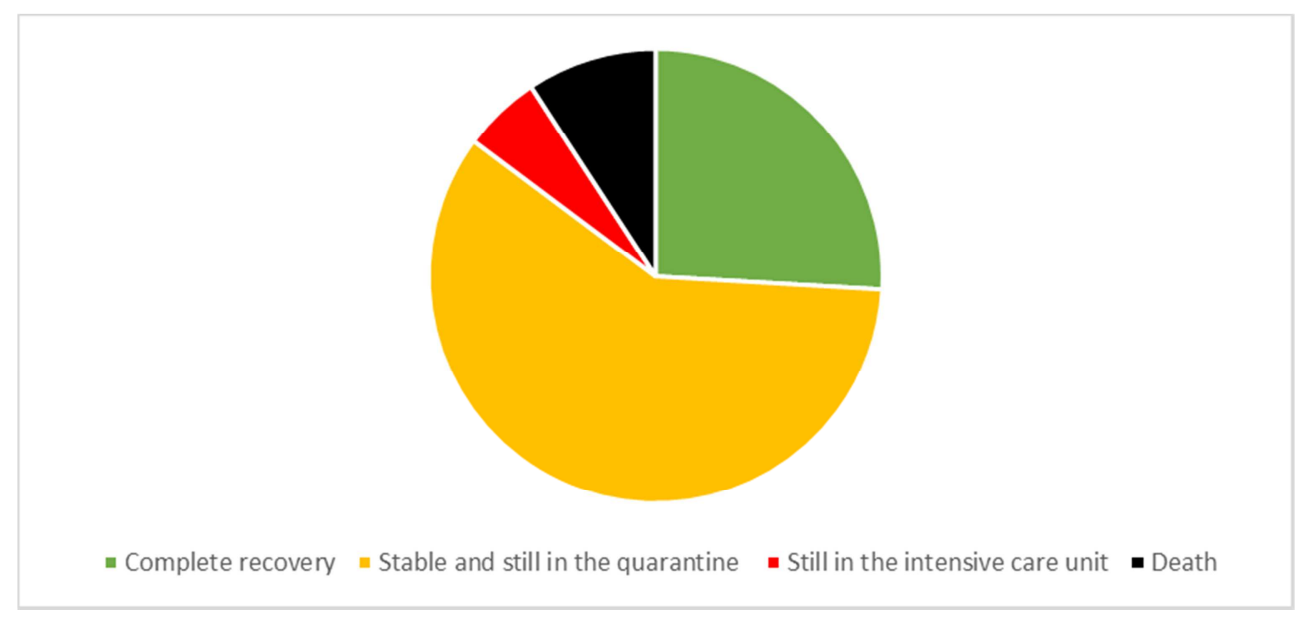

Figure 2. The fate of the COVID-19 patients.

A total of 128 doctors were enrolled in the study to understand the high case fatality rate of COVID-19 in Iraq. All of them work at least 24hours/week in a hospital.

During the period of this study, the 128 doctors who participated in this study encountered a total of 408 patients who were suspected of being COVID-19 positive and notified the specialized authorities about them. From these cases, only $344(82.3 \%)$ patients were actually examined, quarantined and specifically tested for coronavirus.

Most of the doctors $(76.6 \%)$ pointed to the unclear instructions or guidelines ordered by the authorities regarding the patients who enrolled in COVID-19 screening. As seen in the figure 3 .

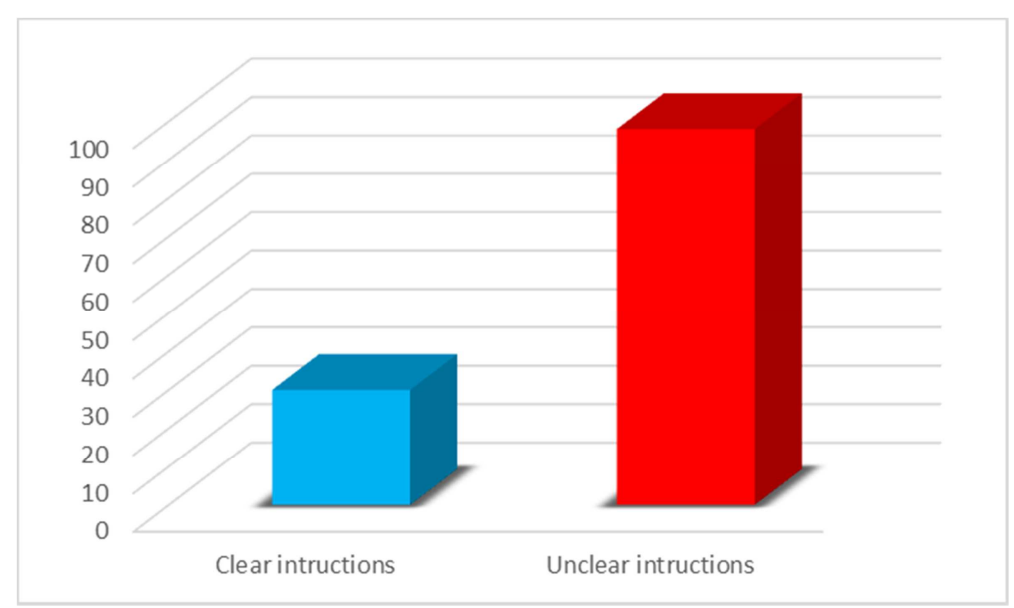

Figure 3. Evaluation of specialized authorities' instruction regarding the patient who enrolled in COVID-19 screening.

In the following paragraph, this study tries to qualify the awareness of Iraqi citizens regarding COVID-19 from the perspective of Iraqi doctors who dealt with them in hospitals across Iraq.

The statistics tools used to describe this paragraph were represented by Likert scale in which the answers are divided into five categories ranged from very weak to very good.

Regarding the awareness on the coronavirus in Iraqi citizens, the results shown in the figure 4 and table 3 show that the mean (1.7031), which indicated that the sample responses were the most between Weak and very weak, almost, and this indicates a very low level of the awareness. Regarding the standard deviation and the coefficient of variance, they are relatively high, indicating a high difference between respondents about the content of this paragraph as shown in figure 4.

Table 3. The awareness of Iraqi citizens regarding COVID-19.

\begin{tabular}{|c|c|c|c|c|c|}
\hline Questions & Very weak & weak & Acceptable & good & Very good \\
\hline $\begin{array}{l}\text { What is your evaluation on the level of health awareness on the corona virus in Iraqi } \\
\text { citizens? }\end{array}$ & 71 & 30 & 18 & 6 & 3 \\
\hline
\end{tabular}




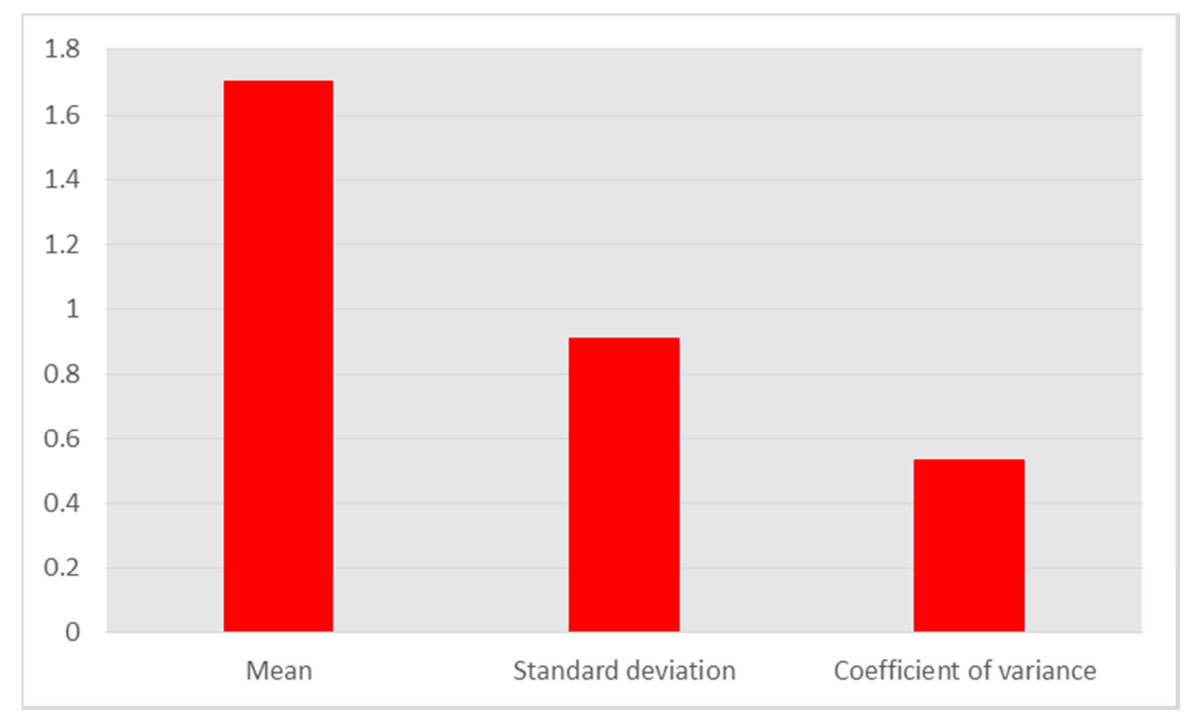

Figure 4. The awareness of Iraqi citizens regarding COVID-19.

\section{Discussion}

The case fatality rate in Iraq was $7.1 \%[10,11]$, which seems to be extremely high in comparison with most countries.

The high case fatality rate is mostly related to three major reasons:

First: according to the ministry of health, the total patients who underwent a diagnostic test for COVID-19 from the time of the 1 st case diagnosis till March $17^{\text {th }} 2020$ was 1679 person only [18] (42 tests per million Iraqi people) this limited number of screening makes the number of confirmed cases low which reflects the high case fatality rate, and if the screening test expanded, we expect the number of confirmed cases to increase progressively and the case fatality rate will decrease.

Second: Most of the doctors complain that the guidelines and instruction regarding the patients who were involved in COVID19 test were not obvious $(76.6 \%$ of doctors who participated in the study) and a large number of suspected cases who were reported to specialized authorities were not tested for COVID-19 ( $17.7 \%$ of cases encountered by the participant).

Third: the low level of awareness among the Iraqi population regarding COVID-19 made most of them not visiting the specialized center or hospital with early symptoms nor notify the specialized authorities regarding their state and this explains the reason of most deaths occurring in the first 24 hours of presentation and also explains the low number of confirmed cases in comparison with the high number of deaths.

All these factors make Iraq one of the highest case fatality rate in the world since many of patient may be positive for COVID-19 and completely asymptomatic (in the incubation period).

The major limitation of this study was the difficulty in performing programmed follow up of the patients in quarantine during the study period for further assessment and many of the data based on the patient's initial presentation in the hospital. Regarding the prognosis, since many patients remained in the hospital and the outcome is unknown at the time being, the clinical outcomes of the patients are based on their status at the time of this analysis.

\section{Conclusions and recommendations}

The COVID-19 disease has been a global pandemic and affects most countries in the world.

Most of the patients were between 30-60 years, however, the highest mortality rate is seen in patients above 50 years. Especially in a patient who had other systemic diseases like diabetes mellitus, hypertension, etc.

In a previously healthy individual, the disease takes a benign course and most of them did not require an aggressive intervention.

In the current study, fever was the most common presentation of the patient with or without cough, shortness of breath. Abnormal chest X-ray finding with lymphopenia is seen in more than half of the patients.

The high fatality rate which is seen in Iraq is related to the limited number of the COVID-19 screening test, unclear guidelines regarding the patients who should been included in the COVID-19 testing, many of the suspected cases which were reported by doctors were not tested, and finally the low level of awareness and late presentation of the patients; all those factors together contribute to such fatality rate.

This study recommends the following to limit COVID-19 outbreak:

It is important to expand the test for COVID-19 to involve all the suspected cases and their close contacts, all medical staff, all the patients in Iraqi hospitals especially those who are immune compromised and then expanded to involve the general population, since many of patient may be positive for COVID-19 and completely asymptomatic (in the incubation period).

Provide the medical staff with clear guidelines regarding 
the patients who should be enrolled in COVID-19 testing and provide them with adequate facilities to protect them.

Enhancing the level of awareness in the general population by providing them with adequate information regarding the disease symptoms, disease burden and the importance of early medical advice and advise them to avoid crowding.

Ethical Consent: Ethical approval for this study was obtained from every patient either directly or through his physician before participation in the study.

\section{Conflict of Interest}

The authors declare that they have no competing interests.

\section{Acknowledgements}

To all Iraqi doctors who are facing death to save our lives... especially those who have participated in this research, many of them today are in quarantine. May God protect you. Our hearts are with you.

\section{References}

[1] Huang C, Wang Y, Li X, et al. Clinical features of patients infected with 2019 novel coronavirus in Wuhan, China. Lancet 2020; 395: 497-506.

[2] Lu R, Zhao X, Li J, et al. Genomic characterization and epidemiology of 2019 novel coronavirus: implications for virus origins and receptor binding. Lancet 2020; 395: 565-74.

[3] Iraqi Ministry of health. Official page on February $24^{\text {th }} 2020$ (https://moh.gov.iq/index.php?name $=$ News\&file $=$ article\&sid $=$ 13908).

[4] World Health Organization. WHO Director-General's opening remarks at the media briefing on COVID-19 - March $11^{\text {th }}$ 2020 (https://www.who.int/dg/speeches/detail/who-directorgeneral-s-opening-remarks-at-the-media-briefing-on-COVID19---11-march-2020).

[5] Pneumonia of unknown cause - China: disease outbreak news. Geneva: World Health Organization, January $5^{\text {th }} 2020$ (https://www.who.int/csr/don/05-January-2020-pneumonia-ofunkown-cause-china/en/).

[6] W. Guan, Z. Ni, Yu Huand their co-workers Clinical Characteristics of Coronavirus Disease 2019 in China. $\begin{array}{lll}\text { February } & 28^{\text {th }} & 2020 .\end{array}$ (https://www.nejm.org/doi/full/10.1056/NEJMoa2002032).
[7] Centers for disease control and prevention. March $14^{\text {th }} 2020$ (https://www.cdc.gov/coronavirus/2019-ncov/symptomstesting/symptoms.html).

[8] $\mathrm{Ng}$, Marimuthu, Leo, and Lee.Evidence of SARS-CoV-2 Infection in Returning Travelers from Wuhan, China. February $18^{\text {th }}$ 2020. (https://www.nejm.org/doi/full/10.1056/NEJMc2001899).

[9] REUTERS investigations (The former minister of health). Iraq's healthcare system is in crisis. March $2^{\text {nd }} 2020$. (https://uk.reuters.com/investigates/special-report/iraq-health).

[10] Iraqi Ministry of health. Official page On April $1^{\text {st }} 2020$ (https://moh.gov.iq/index.php?name $=$ News $\&$ file $=$ article $\& i d=1$ 4168).

[11] Johns Hopkins Coronavirus Resource Center. On April $1^{\text {st }}$ 2020 (https://coronavirus.jhu.edu/map.html).

[12] Novel Coronavirus Pneumonia Emergency Response Epidemiology Team. Vital surveillances: the epidemiological characteristics of an outbreak of 2019 novel coronavirus diseases (COVID-19) - China, 2020. China CDCWeekly. $\begin{array}{llll}\text { Accessed } & \text { February } & 20 & \text { th }\end{array}$ (http://weekly.chinacdc.cn/en/article/id/e53946e2-c6c4-41e99a9b-fea8db1a8f51).

[13] Coronavirus disease 2019 (COVID-19): situation report - 36. Geneva: World Health Organization, February $25^{\text {th }} 2020$ (https://www.who.int/docs/defaultsource/coronaviruse/situation-reports/20200225-sitrep-36COVID-19.pdf?sfvrsn=2791b4e02).

[14] World Health Organization. Coronavirus disease (COVID-19) technical guidance: Laboratory testing for $2019-\mathrm{nCoV}$ in humans (https://www.who.int/emergencies/diseases/novel\%ADcoronavirus-\%AD2019/technical$\% A D$ guidance/laboratory-\%ADguidance).

[15] LaFleur-Brooks M. Exploring Medical Language: A StudentDirected Approach (7th Ed.). St. Louis, Missouri, US: Mosby Elsevier. (2008).

[16] Joseph R. Biggs PhD, Dong-Er Zhang PhD, Molecular Basis of Lymphoid and Myeloid Diseases, Molecular Pathology (Second Edition), (2018).

[17] Katie M. Boes, Amy C. Durham, -Bone Marrow, Blood Cells, and the Lymphoid/Lymphatic System, in Pathologic Basis of Veterinary Disease (Sixth Edition), (2017).

[18] Iraqi Ministry of health. Official page On March $17^{\text {th }} 2020$ (https://moh.gov.iq/index.php?name $=$ News \&file $=$ article \&id $=1$ 4196). 